\title{
A construção da Lei de Acesso à Informação Pública no Brasil: desafios na implementação de seus princípios
}

Eneida Bastos Paes

\section{Introdução}

O Estado moderno, como ensina Weber, é uma construção histórica que pode ser vista como a acumulação monopolista do poder pelos monarcas e concentração desse poder dentro dos limites de um território definido (WEBER, 1994).

Como mostra Giddens (1985), essa concentração de poder é somente conseguida com o acúmulo de informações (administrativas, geográficas, epidemiológicas etc.) pelo Estado. Não é por outra razão que o Estado moderno é caracterizado por um corpo de funcionários especializados, capazes de manipular essas informações de maneira a produzir os instrumentos de dominação legítima. Para o autor, as "sociedades modernas" foram "sociedades de informação” desde seu início.

A manipulação e a armazenagem da informação desempenharam (e desempenham) papel fundamental na constituição (e manutenção) desses Estados. Esse processo de acumulação de informações, por meio de um conjunto de práticas 
administrativas, foi denominado por Foucault (2007) de "gouvernementalité" (que livremente traduzo como governabilidade).

Assim, embora o armazenamento e manipulação da informação seja parte importante da constituição daquilo que se entende por "Estados modernos", somente em período recente iniciou-se um movimento de regulamentação do acesso a essas informações.

O direito de acesso à informação é um tema relativamente novo no cenário internacional e nacional e, portanto, está ainda em fase de consolidação. A doutrina do direito à informação nasceu como consequência de uma "reflexão crítica dentro do pensamento liberal e democrático sobre os problemas sócio-políticos decorrentes da aplicação da liberdade de informação no contexto social pós II Guerra Mundial"1 (JÁuregui, 2011, p. 31, tradução nossa).

Dada a importância do tema, nas últimas duas décadas, houve um crescente movimento de criação, revisão e atualização das leis de acesso à informação em países das Américas, da Europa, da África e da Ásia (ACKerman; SAndoval, 2007).

Segundo Ackerman e Sandoval (2007), há 20 anos somente dez nações no mundo contavam com leis que garantiam aos cidadãos o direito de acesso à informação pública governamental. Desde então, até o ano de 2007, 52 nações a mais já aprovaram leis de acesso à informação. Hoje são cerca de 90 os países com leis de acesso em vigor (MARTINS, 2011).

$\mathrm{O}$ direito de acesso às informações governamentais no Brasil, até recentemente, permanecia incompleto, devido, entre outras coisas, a uma interpretação restritiva daquilo que prevê o Artigo 5 , Inciso XXXIII, da Constituição Federal. Entre o dever de sigilo e o direito à informação, a burocracia permanecia acuada, pois não possuía parâmetros legais suficientes para fundamentar as respostas aos pedidos de informação.

Com a aprovação recente da Lei $\mathrm{n}^{\circ} 12.527$ (Lei de Acesso), em 18 de novembro de 2011, o Brasil possui agora uma legislação infraconstitucional que regulamenta esse direito de forma mais completa. Porém, a nova legislação, se não for acompanhada por uma política pública, dificilmente será suficiente para a ampliação do acesso às informações governamentais.

O presente artigo pretende mostrar, de forma sintética, a experiência do México e Estados Unidos da América na implementação de suas políticas de acesso. As legislações desses países influenciaram fortemente a construção da nova lei de acesso no Brasil. Assim, a experiência desses países fornece algumas pistas sobre as dificuldades que se farão presentes na implementação da nova legislação no Brasil.

\section{As leis de acesso do México e dos Estados Unidos da América}

No México, a lei de acesso é relativamente nova. A lei mexicana entrou em vigor em 2003 e traz, em seu corpo, conceitos e princípios que seguem as orientações dos organismos internacionais para a elaboração de leis de acesso à informação. Além disso, tem um texto claro e detalhado, de fácil compreensão para o cidadão.

$\mathrm{O}$ direito de acesso à informação foi consagrado na Constituição do México com a reforma de 1977, quando o Artigo $6^{\circ}$ foi emendado para incluir em seu texto a ordem segundo a qual o direito de acesso à informação será garantido pelo Estado (GALEANA, 2007). 
No ano de 2002, uma abrangente emenda ao Artigo $6^{\circ}$ da Constituição mexicana, aprovada por unanimidade pelas duas câmaras do Congresso e pela legislatura de 16 estados, ampliou substancialmente a proteção constitucional ao direito de acesso à informação no país.

Contudo, mesmo antes da aprovação das referidas emendas constitucionais, o México já contava com uma lei de Direito à Informação que figurava entre as mais progressistas do mundo. Como relata Mendel (2009), a garantia constitucional aprovada por essas recentes emendas ao texto da Constituição mexicana fez com que o país fique no cenário mundial, em matéria relacionada ao direito de acesso, somente atrás do sistema constitucional sueco.

Para organizar os pedidos de acesso à informação nos diversos órgãos do Estado, a Lei Federal de Transparência mexicana criou as chamadas "Unidades de Enlace", onde é possível solicitar informação pessoalmente. As Unidades de Enlace funcionam nas dependências de cada entidade pública para atender às demandas de acesso à informação. Nessas unidades, ou por meio eletrônico, podem ser requeridas informações governamentais, mesmo que ainda não tenham sido publicadas (Artigo 40). Feito o pedido de acesso, e tendo sido negado, é possível recorrer da decisão administrativamente (Artigo 49) e judicialmente, quando o recurso administrativo for denegado.

Mas a Lei Federal de Transparência mexicana, por si só, e mesmo as emendas constitucionais aprovadas no México não garantem o efetivo exercício do direito que prescrevem. Como dito à época da entrada em vigor da Lei Federal de Transparência: "O texto da Lei é bem escrito e bem concebido. O teste crítico vem agora na implementação"2 (RELly, 2003, p. 38, tradução nossa).
Em estudo sobre a aplicação da Lei de Acesso à Informação no México, os pesquisadores do Centro Internacional de Estudios de Transparencia observaram que a disponibilidade e o entusiasmo para participar do estudo que estavam realizando, entre os funcionários entrevistados, foram bem menores que a disposição entre os chefes das Unidades de Enlace (Centro Internacional de Estudios de Transparencia y Acceso a la Información - Ceta, 2007).

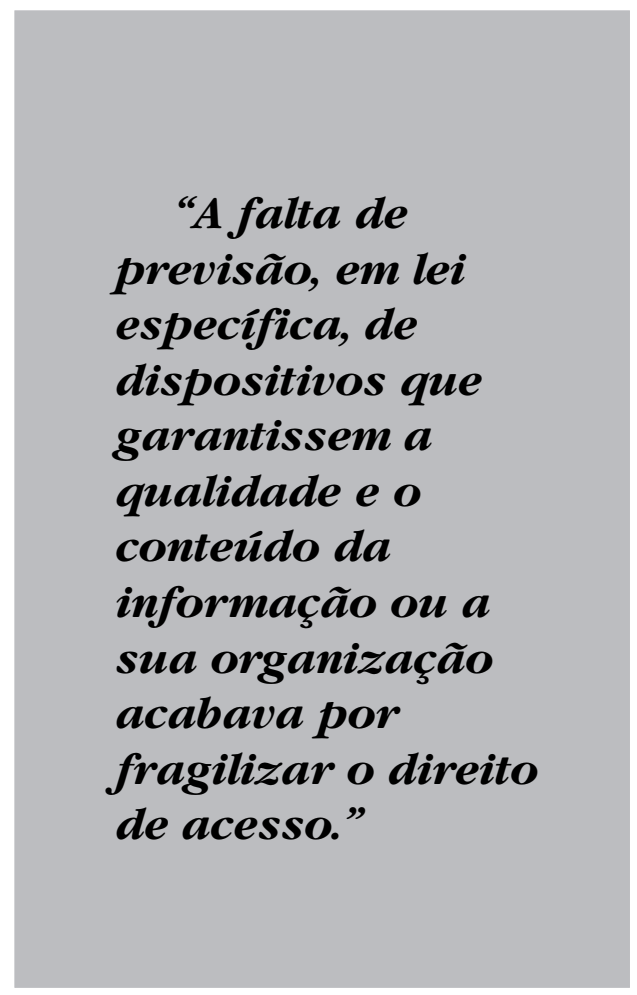

Uma das conclusões apresentadas no estudo do Ceta foi a de que não existe uma cultura de transparência e acesso à informação claramente estabelecida entre os servidores e, ainda, que "a cultura dos funcionários é mais burocrática e hierárquica, sem demonstrar qualquer processo de grande alteração para a implementação da Lei"3 (Centro Internacional de Estudios de 
Transparencia y Acceso a la Informacion Ceta -, 2007, grifos no original, tradução nossa).

Nos Estados Unidos da América, a legislação sobre o direito de acesso à informação está consolidada no Freedom of Information Act (Foia), que data de 1966. A Lei abrange o Poder Executivo federal e estabelece as normas de caráter administrativo e procedimental. Trata-se de uma norma de caráter administrativo, com foco nos procedimentos, prazos e meios de acesso à informação. A estrutura e a linguagem utilizada na norma são técnicas, voltadas para orientação mais da burocracia que do cidadão.

A criação do Freedom of Information Act, em 1966, não representou, em si, uma novidade na comunidade internacional (a Suécia e a Finlândia já tinham leis mais antigas sobre o direito de acesso à informação). O ponto relevante dessa norma é a abrangência do conceito de informação, pois muitos documentos que estão enquadrados na legislação do Foia - Lei Federal de Acesso à Informação estadunidense - não seriam considerados "oficiais" pelas leis sueca ou finlandesa (Roberts, 2006). Além disso, conforme destacado por Kettl (apud Mendanha, 2009, p.62), "a lei (Foia) inverte o tradicional ônus da prova, passando da suposição de que os documentos eram confidenciais até que os cidadãos conseguissem estabelecer fundamentos para ter acesso a eles, para a suposição de que os documentos são públicos até que o governo estabeleça uma base (como segurança nacional e privacidade pessoal) para mantêlos em sigilo".

Essas características, junto à facilidade de obtenção das informações pela via administrativa - reservando-se a via judicial apenas para casos de recurso -, favorecem a efetivação do direito de acesso à informação no país. Somente no ano de 2010 foram cerca de $600 \mathrm{mil}$ pedidos de acesso à informação (UNITED States Department Of Justice, 2011).

Outro fato que deve ser observado, e que pode vir a gerar problemas para a burocracia no atendimento dos requerimentos, é o universo de informações geradas pelo governo. O Escritório de Serviços de Informação do Arquivo Nacional dos Estados Unidos já fala em "US gov information inflation", tamanho ou número de e-mails (30 bilhões por ano), além de documentos multimídia, fotografias, mapas, databases, gravações de áudio e vídeo e aplicações Web 2.0, armazenados nos arquivos do governo (NisBet, 2011).

O volume de informações para armazenamento, o aumento do universo a ser pesquisado e o grande número de requerimentos recebidos podem ser fatores que levam ao atraso nas respostas ou mesmo à recusa de liberação de acesso. Relatos, contudo, apontam outro fator, de fundo político, que seria o esvaziamento dos escritórios do Foia, com a finalidade de atrasar a liberação das informações.

Uma das coisas mais interessantes sobre a má administração do Foia [Lei Federal de Acesso à Informação Estadunidense] é que, no início da década de 1970, o burocrata do governo é que era o problema. Hoje, existe um núcleo de profissionais tão altamente qualificados na questão do acesso que o problema, agora, reside nos decisores políticos. (...), no nível da política pública, as organizações descobriram que, se cortarem os recursos desses organismos, podem retardar a divulgação de informações. E isso funciona. Tive um cliente que ia apresentar um pedido de acesso baseado no Foia para o Departamento de Justiça 
sobre uma investigação antitruste, mas eu disse para ele esquecer: quando conseguíssemos a informação, ela seria tão obsoleta que teria se tornado absolutamente inútil ${ }^{4}$ (FoERsTEL, 1999, p. $164-$ 65, tradução nossa).

\section{O direito de acesso à informação no Brasil: 1988-2011}

No caso do Brasil, antes da aprovação da Lei de Acesso, Lei n ${ }^{\circ}$ 12.527, de 18 de novembro de 2011, existia uma legislação espaçada que tratava do direito de acesso. Entretanto, ela estava dispersa em diversos dispositivos, que tratavam apenas de forma parcial, direta ou indiretamente, a questão do acesso à informação.

As normas sobre acesso estavam inseridas em leis sobre responsabilidade fiscal, preservação do meio ambiente, sobre a questão da guarda de arquivos, entre outras. Assim, as regras sobre o acesso à informação estavam dispersas em ordenamentos múltiplos e distintos, gerando interpretações divergentes e outras consequências negativas, além de um evidente descompasso com o avanço do tema na legislação de países vizinhos (EsmanHoto, 2010).

A Lei de Responsabilidade Fiscal (BRAsIL, 2000), com as modificações introduzidas pela Lei Complementar $n^{\circ}$ 131, de 2009, embora determinasse que fosse colocada ao dispor da população grande quantidade de informações, atualizadas em tempo real, não se preocupava em determinar a qualidade ou a forma como esses dados eram publicados.

A Lei Ambiental (Brasil, 2003) mostrava-se insuficiente em relação à quantidade de informações que determinava que fossem publicadas espontaneamente pelos órgãos abrangidos pela Lei.
No que se refere às leis que interferem nos procedimentos e processos decisórios internos do governo, a Lei no 11.111 (BRASIL, 2005) e a Lei de Arquivos Públicos (BRASIL, 1991) podem ser tomadas como exemplos de normas que, embora devessem se ocupar em fornecer detalhes sobre a estrutura e organização interna das informações governamentais, sejam elas públicas ou sigilosas, apenas delegavam essa função a normativos inferiores, ou seja, ao gestor, à burocracia estatal.

Assim, até 2011, não havia legislação sobre o direito de acesso à informação, pois a Lei $\mathrm{n}^{\circ}$ 11.111, de 2005, apenas regulamentava o sigilo das informações governamentais - a parte final do Art. $5^{\circ}$, Inciso XXXIII, da Constituição Federal. A falta de previsão, em lei específica, de dispositivos que garantissem a qualidade e o conteúdo da informação ou a sua organização acabava por fragilizar o direito de acesso.

Ademais, a delegação feita nas leis para que existam regulamentação de prazos e procedimentos de acesso por decretos ou outros normativos infralegais, além de poder ser consideradas inconstitucionais, também poderiam levar à excessiva intervenção política e administrativa, com vistas a obter o controle ou a direção do conteúdo da informação (JÁuREgui, 2011, [s.n.]).

Essa falta não pode ser atribuída à inexistência de previsão constitucional. O Inciso XXXIII do Artigo $5^{\circ}$ da Constituição Federal de 1988 não só prevê o direito de acesso à informação, como, ainda, determina a criação de lei para regulamentar o assunto. Além disso, o tema também está previsto no princípio da publicidade, inscrito no Artigo 37 da Constituição (BRASIL, 1988).

A partir da Constituição de 1988, a transparência e a publicidade eram 
princípios que deveriam nortear a relação do Estado com a população. Se "durante o período ditatorial, valia a regra de que toda informação era imprescindível à segurança nacional", com a Constituição de 1988, passou a valer a regra de que toda informação é pública, "a não ser que seja considerada restrita por questões de segurança” (LOPES, 2007, p. 5).

A falta de regulamentação da parte do dispositivo constitucional referente ao acesso e do detalhamento da parte referente ao sigilo (por meio da Lei no 11.111, de 2005, revogada pela Lei de Acesso) pode ter frustrado algumas das expectativas geradas com a promulgação da Constituição de 1988, conforme relatado por Cepik:

Após a promulgação da Constituição houve certa agitação na opinião pública e alguns pedidos de informação sobre situações pessoais, logo frustrados por um parecer da Consultoria Geral da República (no SR-71), que deixava a cargo do chefe do antigo Serviço Nacional de Informações (SNI) a avaliação sobre quais dados poderiam ser divulgados, em função da ressalva de sigilo prevista no Inciso XXXIII do Artigo $5^{\circ}$ da Constituição (CEPIK, 2011, p. 43).

Por tudo isso, se fazia necessária a criação de uma lei própria para tratar do direito de acesso à informação no Brasil.

\section{A construção da lei de acesso à informação no Brasil}

No Brasil, seguindo a esteira de países de democracias recentes, surgiram muitos projetos de lei, no Senado Federal e na Câmara dos Deputados, visando regulamentar o direito de acesso. Entretanto, como mostraremos, as principais diretrizes do Projeto de Lei que se converteu na Lei $\mathrm{n}^{\circ} 12.527$ (Lei de Acesso) foram discutidas e propostas em uma disputa que ocorreu principalmente na burocracia do Poder Executivo federal.

Essa discussão se iniciou em 2004, a partir do Projeto de Lei no 219/2003, do deputado Reginaldo Lopes, do PT/MG, que buscou apoio junto à ControladoriaGeral da União (CGU), no sentido de viabilizar seu projeto no Congresso. Esse fato iniciou uma discussão intragovernamental, que culminou na revisão da legislação e na criação de um projeto de lei do Poder Executivo federal - que foi aprovado recentemente pelo Congresso e tornou-se, assim, a nova Lei de Acesso brasileira.

Inicialmente, essa discussão ficou restrita à Controladoria-Geral da União (CGU), primeiro no Gabinete do ministro e, depois, no Conselho da Transparência Pública e Combate à Corrupção (CTPCC) órgão paritário com representantes do governo e da sociedade civil, vinculado à CGU. No CTPCC, o anteprojeto foi amplamente debatido, ampliado e melhorado e seguiu para a Casa Civil.

Depois, em 2006, também o Ministério da Justiça apresentou outra versão de anteprojeto de Lei de Acesso à Informação, com foco na compilação da legislação vigente sobre arquivos e sobre documentos sigilosos. Essas duas versões passaram a ser objeto de estudo de um grupo formado pela Casa Civil, na Presidência da República, para elaborar o Projeto de Lei de Acesso à Informação do Poder Executivo federal.

De 2006 a 2007, iniciou-se, então, uma intensa discussão coordenada pela Casa Civil, que criou, informalmente, um grupo de técnicos de diversos órgãos do Executivo federal para debater as propostas de 
criação de uma lei para regulamentar o direito de acesso à informação no Brasil. A CGU, o Ministério da Justiça, o Ministério da Defesa, o Ministério das Relações Exteriores, entre outros, foram chamados para integrar esse grupo, que foi incumbido de fazer uma minuta de projeto de lei sobre acesso à informação.

A redação final do Projeto de Lei de Acesso foi de responsabilidade da Casa Civil, que arbitrou algumas disputas internas entre os envolvidos e formatou a versão final do Projeto de Lei. Esse Projeto foi enviado, em maio de 2009, ao Congresso Nacional.

Na Câmara dos Deputados, a iniciativa do Executivo tramitou na forma do Projeto de Lei n ${ }^{\circ}$ 5.228/2009 (PRESIDÊNCIA DA RepúBLICA, 2009). Na Câmara, o projeto de lei citado recebeu as principais modificações, na forma de um substitutivo ao Projeto de Lei enviado pelo Poder Executivo.

A Comissão Especial de Acesso a Informações da Câmara dos Deputados aprovou o Substitutivo apresentado pelo deputado Mendes Júnior. De modo geral, as principais inovações desse projeto dizem respeito ao escopo da legislação, à possibilidade de prorrogações de sigilo e ao processo de revisão das decisões administrativas denegatórias de acesso.

O Projeto de Lei no 5.228/2009 já estabelecia obrigações a todos os órgãos e entidades públicas, deixando subentendida sua aplicação a todos os poderes (Executivo, Legislativo e Judiciário) dos três entes federativos. O Substitutivo torna esse entendimento expresso e detalha, em seu Artigo $1^{\circ}$, os órgãos e entidades públicas sujeitos à aplicação da Lei (incluindo, nesse escopo, tribunais de Contas, Ministério Público e até mesmo entidades privadas, desde que recebam recursos públicos).
O Substitutivo deixa claro que a Lei estipula normas gerais a serem observadas pela União, estados e municípios, dispondo, ainda, sobre a necessidade de os estados, Distrito Federal e municípios disciplinarem em legislação própria o funcionamento do serviço de informações ao cidadão (Artigo $9^{\circ}$ ) e o procedimento de recurso, no caso de indeferimento de acesso às informações ou às negativas de acesso (Seção II do Capítulo III).

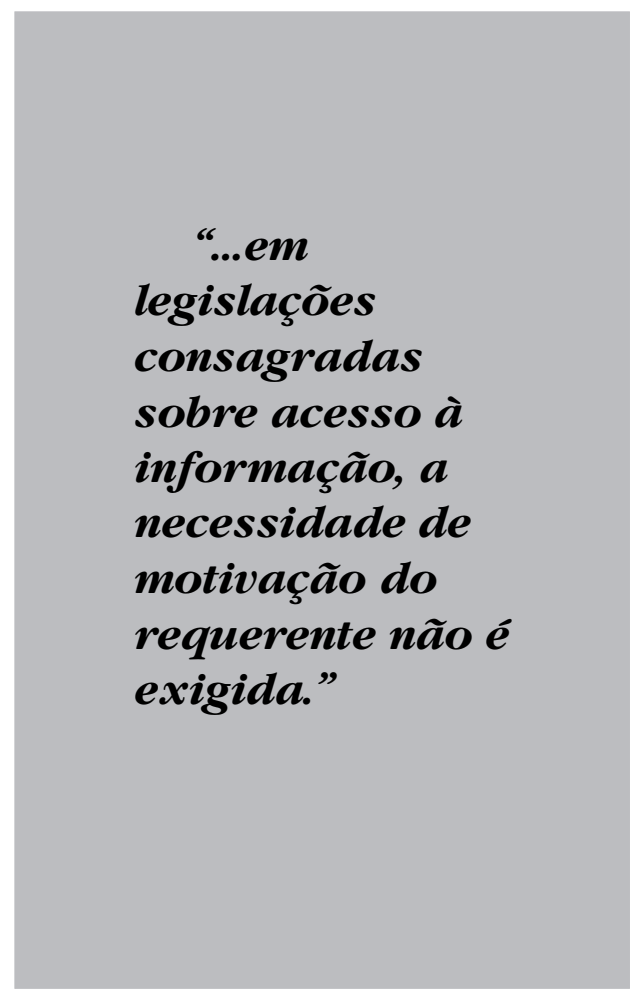

Alteração significativa realizada pelo Substitutivo é a restrição imposta à atribuição da Comissão de Reavaliação de prorrogar o prazo de sigilo de informações classificadas como ultrassecretas no caso de ameaça externa à soberania nacional ou à integridade do território nacional, ou grave risco às relações internacionais do país. O Projeto de Lei no 5.228/2009 (original) 
deixava essa possibilidade de prorrogação em aberto, ou seja, não fixava número máximo de prorrogações. O Substitutivo, por sua vez, determina que a prerrogativa da Comissão de Reavaliação fosse limitada a uma única renovação, evitando, assim, prorrogações sucessivas, que valorizariam o segredo em detrimento do princípio da ampla publicidade.

Por fim, o Substitutivo estabelece que os procedimentos de revisão de decisões denegatórias serão objeto de regulamentação própria no Poder Legislativo, no Poder Judiciário e no Ministério Público, assegurado ao solicitante, em qualquer caso, o direito de ser informado sobre o andamento de seu pedido. Os órgãos do Poder Judiciário e do Ministério Público deverão informar ao Conselho Nacional de Justiça e ao Conselho Nacional do Ministério Público, respectivamente, as decisões que, em grau de recurso, negarem acesso a informações de interesse público.

Além das mudanças com relação aos órgãos afetados pela Lei, ao tempo de guarda dos documentos sigilosos e ao encaminhamento dos recursos administrativos, também foram feitas alterações nos dispositivos que tratam da utilização da Internet para a divulgação de informações; das autoridades competentes para a classificação de documentos sigilosos; da lista de documentos sigilosos; da revisão periódica dos documentos sigilosos e do prazo para a vacatio legis.

Terminada a tramitação na Câmara dos Deputados, com a aprovação das modificações inseridas pelo Substitutivo, o Projeto de Lei seguiu para o Senado Federal, onde tramitou como PLC 41/2010 (Senado Federal, 2010). No Senado, passadas diversas comissões, veio à tona a discussão a respeito das informações sigilosas, e a possibilidade de renovação dos seus prazos máximos de guarda foi posta em outro Substitutivo, apresentado pelo senador Collor de Mello na Comissão de Relações Exteriores e Defesa Nacional. As principais mudanças propostas relacionadas às informações sigilosas pretendiam que a classificação das informações voltaria a ter quatro níveis (como estava previsto na legislação vigente à época). Também foi proposta a renovação dos prazos de guarda de documentos, que poderiam, nos termos do Substitutivo do Senado, ser prorrogados por tempo indeterminado, sempre que "imprescindível à segurança da sociedade e do Estado"; e a ampliação do rol de autoridades responsáveis pela classificação.

Todas essas propostas de modificações, importantes e substanciais, fizeram com que o texto do Projeto de Lei de Acesso ficasse tramitando no Senado por mais de dois anos. Mas, ao final, as propostas feitas por meio do Substitutivo do Senado foram rejeitadas e seguiu para sanção presidencial o texto do Substitutivo construído na Câmara dos Deputados. Essa demora, contudo, significou maior tempo de maturação do texto normativo. É importante ressaltar que existiram de fato análise e debate democrático sobre o acesso à informação. As ideias foram postas e os pontos de vista, amplamente debatidos.

O que importa ressaltar, para fins deste trabalho, é que o texto final da Lei de Acesso à Informação brasileira finalmente reuniu em um só diploma as principais disposições sobre $\mathrm{o}$ assunto e, ainda, sugeria a revogação das normas conflitantes.

Outro fato que se destaca é que grande parte do texto publicado da Lei de Acesso permaneceu fiel ao texto escrito inicialmente no âmbito interno da burocracia de Estado. Os desafios da burocracia para a implementação desta Lei, em grande parte, foram postos por seus 
próprios representantes. Mas houve modificações importantes no texto quando da tramitação do Projeto da Lei de Acesso na Câmara dos Deputados e, ainda, discussões extensas sobre a questão das informações sigilosas no Senado Federal.

\section{Inovações da Lei de Acesso para a cultura administrativa brasileira}

Embora as discussões sobre as informações sigilosas tenham dominado os debates no Congresso e na mídia quando se falava no projeto de Lei de Acesso, vale destacar outros pontos que são importantes para assegurar o direito de acesso às informações públicas, ou seja, as informações que não estão classificadas como sigilosas.

As principais inovações da Lei de Acesso à Informação para a administração pública, embora pareçam pequenas, são tão importantes quanto as referentes ao sigilo. São inovações referentes ao modo de elaboração dos requerimentos de informação, à tramitação dos requerimentos, estipulação de prazos e penalidades para o descumprimento. Quanto maior o número de exigências que se faz ao requerente e maior a atribuição de discricionariedade ao administrador, menor será o acesso à informação.

O $\int 3^{\circ}$ do Art. 10 da Lei de Acesso (Brasil, 2011) diz que "São vedadas quaisquer exigências relativas aos motivos determinantes da solicitação de informações de interesse público.” Uma breve análise desse dispositivo revela que, em legislações consagradas sobre acesso à informação, a necessidade de motivação do requerente não é exigida. $\mathrm{Na}$ legislação da Suécia (Sweden, 2011), que data do século XVIII, chega a ser proibido perguntar o nome do requerente, que dirá sua motivação. Está claro que a redação dada a esse dispositivo da Lei de Acesso (BrasiL, 2011) não pretendia fazer um "transplante" da legislação internacional, mas adaptou o conceito à realidade e cultura administrativa brasileiras.

Existem, de fato, na doutrina nacional, autores que defendem a necessidade de justificativa dos pedidos de acesso, para evitar o que chamam de pedidos "abusivos" e para que o administrador possa "avaliar se a máquina estatal não estará sendo acionada de modo desnecessário, impertinente ou irrazoável" (LEVY, 2009). Não há como concordar com essa corrente. A discricionariedade não pode chegar a tanto, tratando-se do exercício de um direito fundamental, "na qualidade de patrimônio subjetivo indisponível pelo poder, são os direitos e liberdades que limitam a lei, não é a lei que cria e dispõe dos direitos fundamentais" (CANOTILHO, 1999). E, especialmente quando se trata de acesso à informação, a impropriedade da imposição de justificativa da solicitação de acesso parece ser posição unânime entre os autores pesquisados. Assim, temos as seguintes posições:

Deverá ser proibida expressamente toda formulação que dê indícios de questões sensíveis ao recorrente e/ou que resultem em questões sobre as motivações do pedido e seu uso posterior $^{5}$ (Pierini; Lorences, 1999 , p. 242, tradução nossa).

Sobre o direito "ao arquivo aberto" previsto na legislação portuguesa, Canotilho (1999) diz que:

a Constituição não faz depender a liberdade de acesso aos documentos administrativos da existência de um interesse pessoal (...) a ideia de democracia participativa aponta não só para 
um direito de acesso aos arquivos e registros públicos para defesa de direitos individuais, mas também para um direito de saber o que passa no âmbito dos esquemas político-burocráticos, possibilitando ao cidadão o acesso (...) circulares, notas, etc. (CANOTILHO, 1999, p. 679).

Uma posição intermediária é apontada por Saba (2004). Para este autor, quando os motivos forem importantes para facilitar a busca da informação requerida, "pode" ser apresentada motivação do pedido, a critério do solicitante, do requerente - a quem cabe "calcular o quanto perde e o quanto ganha manifestando as razões pelas quais está solicitando a informação" "S (SABA, 2004, p. 171, tradução nossa).

Um dos mecanismos possíveis para se evitar pedidos amplos ou genéricos demais (que nem sempre têm a intenção de ser abusivos, mas demonstram apenas falta de familiaridade do requerente com o assunto), é a orientação de servidores treinados, que poderão entrar em contato com $o$ requerente para tentar especificar mais o pedido. $\mathrm{Ou}$, ainda, disponibilizar o maior número de dados abertos para que o requerente extraia e organize, ele mesmo, os dados da forma como necessita.

Quanto à tramitação dos requerimentos de acesso, vale destacar o detalhamento trazido pela Lei, que garante ao requerente o direito de obter o teor de decisão de negativa de acesso, por certidão ou cópia. Mas inova a Lei especialmente na seção sobre recursos, que cria uma instância recursal procedimental à parte. Nessa seção foi determinado à Controladoria-Geral da União (CGU) que delibere sobre: a negativa do acesso à informação não classificada como sigilosa; sobre a qualidade da decisão de negativa de acesso à informação; a qualidade dos procedimentos de classificação de informação sigilosa; e sobre os prazos descumpridos ou outros procedimentos previstos na Lei.

Assim, o controle sobre a administração, para garantir o cumprimento da Lei de Acesso, além de ser feito internamente - pelo órgão ao qual o pedido foi dirigido -, também será feito por outro ente. A Controladoria-Geral da União funcionará como órgão revisor do Poder Executivo federal; nos demais poderes e esferas de governo serão designados órgãos próprios para essa função.

O controle por si só, de fato, não poderá garantir desvios da finalidade da lei e de seu cumprimento. Para tanto, a lei também traz inovações com respeito à responsabilização dos agentes que incidirem nas condutas previstas no Art. 32 da Lei de Acesso, e garante por meio de modificações na Lei no 8.112 , de 1990, maior proteção aos servidores que denunciam irregularidade.

\section{Considerações finais}

A nova Lei de Acesso à Informação é só um passo de todo um processo de formação de uma política de acesso à informação que começa a se desenhar no cenário nacional, por clara influência da comunidade internacional e da burocracia estatal (PAES, 2011). Entretanto, a criação de uma legislação é apenas uma etapa na construção de uma política de transparência no país. A norma deve ser transformada em ações e fatos, pelo Executivo e demais poderes, para sua efetivação, possibilitando maior conhecimento da população sobre os atos do governo, tentando eliminar a desconfiança sem que se perca o interesse. 
À época da construção do Projeto de Lei de Acesso à Informação no Poder Executivo federal, houve uma confluência de fatores que levaram à elaboração do anteprojeto: a iniciativa parlamentar e a expectativa dos membros da sociedade civil representados no Conselho da Transparência Pública e Combate à Corrupção. As pressões internas e externas demonstravam que havia uma carência (um vácuo) a ser preenchida em matéria de acesso à informação no país.

Assim, aprovada a Lei de Acesso, abrem-se as condições para a implementação de uma política pública capaz de garantir esse direito no contexto do Estado brasileiro. Entretanto, a legislação é condição necessária, porém insuficiente para garantir esse direito. Restam ainda todas as regulamentações, que possibilitem a existência (de fato) de uma política pública que garanta o direito de acesso.

Uma das principais questões na implementação diz respeito à "mudança cultural" da burocracia. Essa mudança cultural envolve capacitações dos servidores, estabelecimento de metas, recursos etc. (PAES, 2011).

Em princípio, não parece existir uma resistência da burocracia brasileira em liberar acesso às informações detidas por seus órgãos, embora exista ainda grande desconhecimento, oriundo não somente da novidade da Lei, mas também da falta de capacitação do servidor em relação ao tratamento de arquivos e informações sigilosas. Isso é constatado em pesquisa recente feita pela Controladoria-Geral da União (CGU), em parceria com a Unesco, junto aos servidores do Poder Executivo. A pesquisa tinha como objetivo "avaliar a possível implementação de uma política de amplo acesso à informação pública por parte do cidadão", e mostra que existe uma abertura da burocracia em relação ao assunto. Em síntese, concluem os pesquisadores que o servidor concorda com a implementação do direito de acesso, mas enfatizam que ele precisa conhecer melhor os conceitos e limites relacionados ao tema. De acordo com o relatório, o servidor:

entende que há um distanciamento entre Estado e Sociedade e não apresenta dúvidas quanto ao seu papel de servidor, de fato, público, a serviço do cidadão.

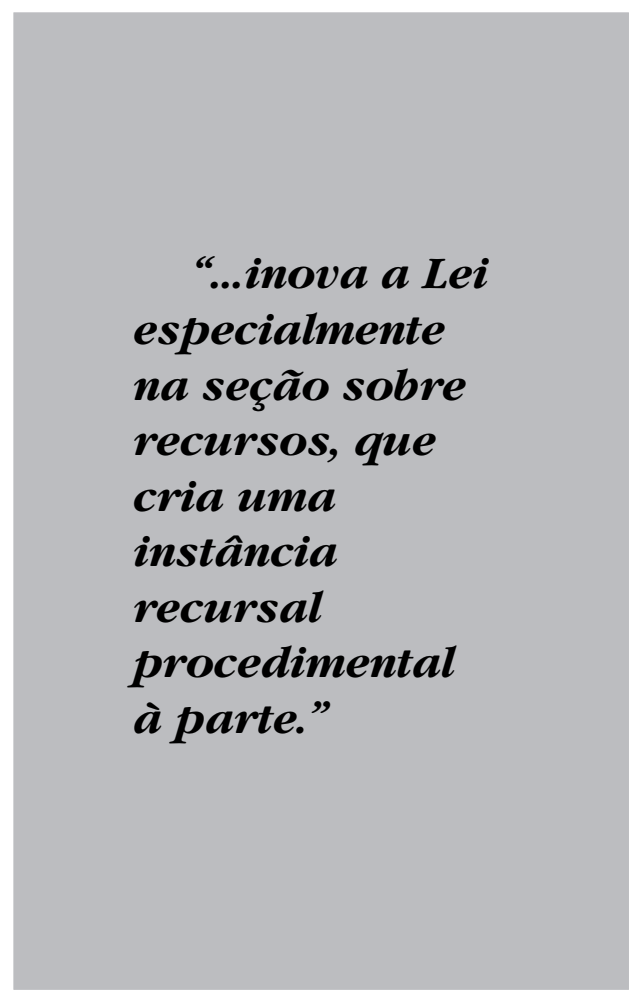

Por isso, não vê problemas quanto à implementação de uma política de amplo acesso, por parte do cidadão, à informação pública. Exceto pelo fato de necessitar de mais informações para conhecer a política (Projeto de Lei) e saber, de fato, o que é "informação sigilosa", pois entende que existam e devam ser preservadas (CONTROLADORIA-GERAL DA UnIão, 2011, grifo nosso). 
O desconhecimento do servidor sobre a política de acesso à informação denota, em última análise, a inexistência de uma política de acesso à informação. A pesquisa revelou que $61,5 \%$ (soma das respostas: "raramente" e "nunca") dos servidores não fazem cursos ou treinamentos nas áreas de gestão de documentos e segurança da informação. O dado aponta para uma lacuna na formação dos servidores em áreas essenciais à realização do direito de acesso à informação. Ou seja, os dados mostram que o servidor considera-se "despreparado" para atuar nessa área.

Um dado sobre a cultura do sigilo na administração pública federal também merece destaque: informa a pesquisa (Controladoria-geral da União, 2011) que o servidor mais jovem (abaixo de 45 anos), com maior nível de escolaridade e que está há menos de 10 anos no serviço público, "se sente à vontade para negar categoricamente o 'sigilo eterno' às informações públicas”. O sigilo eterno é negado por pouco mais da metade dos servidores $(55,5 \%)$, contra $40,7 \%$ a favor do sigilo eterno. Ou seja, ainda não é possível afirmar que existe uma cultura da máxima transparência e publicidade consolidada na administração pública brasileira, pois apenas pouco mais da metade dos servidores são contrários ao sigilo eterno.

De fato, o entendimento da burocracia brasileira em relação ao direito de acesso à informação começa a se desenhar. Surgem as primeiras pesquisas e surgirão também os primeiros sucessos e entraves decorrentes da aplicação da Lei. A implementação da Lei de Acesso à Informação brasileira dependerá do empenho da burocracia, que reage não só movida por seus interesses individuais, mas também pelas condições e pelo contexto político em que está inserida. Havendo interesse político na construção de uma política pública de acesso à informação que dê suporte à nova Lei de Acesso, as condições de implementação da Lei serão mais bem-sucedidas.

Como mostra a experiência internacional descrita neste artigo (experiências dos Estados Unidos da América e do México), existe um contexto político que também influenciará a regulamentação da Lei pelo Poder Executivo. Dependendo desses regulamentos, a Lei poderá ou não extrair uma maior transparência do Estado. Ao mesmo tempo, existe a necessidade de alocação de recursos financeiros e tecnológicos capazes de operacionalizar a política.

$\mathrm{Na}$ implementação da política de acesso é que se verá até que ponto os órgãos abrangidos pela Lei conseguirão traduzir os princípios em condições efetivas de acesso do cidadão às informações governamentais.

(Artigo recebido em agosto de 2011. Versão final em dezembro de 2011).

\section{Notas}

1 "reflexión crítica dentro del pensamiento liberal y democrático sobre los problemas sociopolíticos originados por la aplicación de la libertad de información en el contexto social surgido de la Segunda Guerra Mundial" (JÁuregui, 2011, p.31)

2 "The text of the law is well-written and well-conceived. The critical test comes now in the implementation" (RELLY, 2003, p.38). 
3 "La cultura de los funcionarios es más burocrática y jerárquica sin mostrar ningún proceso mayor de cambio por la implementación de la Ley" (CENTRO InTERnACiONAL DE Estudios De Transparencia Y ACCeso a LA INFORMACIÓN - CetA, 2007, grifos no original).

4 "Thomas Susman (...) pointed out, 'One of the interesting things about the poor administration of the FOIA is that in the early 1970s the government bureaucrat was the problem. Today, there is such a core of highly qualified and competent access professionals that the problem now resides with the policy makers. (...), at the policy level, agencies have found that if they starve these offices they can slow down the release of information. And it works. I had a client who was going to submit a FOIA request to the Justice Department on an antitrust investigation, but I said forget about it. By the time we get the information, it's going to be so stale that it'll be absolutely useless"' (Foerstel, 1999, p.164-65).

${ }^{5}$ Deberá prohibirse expresamente toda fórmula que indique información sobre cuestiones sensibles del recurrente y/o que resulten indagatorias sobre las motivaciones del pedido y su uso posterior (Pierini; LoRenCes, 1999, p. 242)

6 "cálculo acerca de cuanto pierde y cuanto gana manifestando las razones por las que solicita la información” (SABA, 2004, p.171).

\section{Referências bibliográficas}

Ackerman, J.M.; Sandoval, I. E. Leyes de acceso a la información en el mundo. Cuadernos de Transparencia, México, v. 07, 2007.

Brasil. Constituição da República Federativa do Brasil de 1988. Diário Oficial da União, Brasilia, 1988.

- Controladoria-geral da União. Pesquisa: Acesso à Informação Pública Relatório Analítico Conclusivo. Projeto: Política Brasileira de Acesso a Informações Públicas, Brasilia, 30 ago. 2011.

. Lei $\mathrm{n}^{\circ}$ 8.159, de 08 de janeiro de 1991: Dispõe sobre a política nacional de arquivos públicos e privados e dá outras providências. Diário Oficial da União, Brasília, 09 jan. 1991.

. Lei no 8.112, de 11 de dezembro de 1990: Dispõe sobre o regime jurídico dos servidores públicos civis da União, das autarquias e das fundações públicas federais. Diário Oficial da União, Brasília, 12 dez. 1990 e Republicado no D.O.U. de 18 mar.1998. . Lei no 10.650, de 16 de abril de 2003: Dispõe sobre o acesso público aos dados e informações existentes nos órgãos e entidades integrantes do Sisnama. Diário Oficial da União, Brasília, 16 abril 2003.

. Lei no 11.111, de 05 de maio 2005: Regulamenta a parte final do disposto no Inciso XXXIII do caput do Art. $5^{\circ}$ da Constituição Federal e da outras providências. Diário Oficial da União, Brasília, 05 maio 2005.

. Lei $\mathrm{n}^{\circ}$ 12.527, de 18 de novembro de 2011: Regula o acesso a informações previsto no Inciso XXXIII do Art. $5^{\circ}$, no Inciso II do $\int 3^{\circ}$ do Art. 37 e no $\ 2^{\circ}$ do Art. 216 da Constituição Federal; altera a Lei no 8112, de 11 de dezembro de 1990; 
revoga a Lei $\mathrm{n}^{\circ} 11 . .111$, de 5 de maio de 2005, e dispositivos da Lei $\mathrm{n}^{\circ}$ 8.159, de 8 de janeiro de 1991; e dá outras providências. Diário Oficial da União, Brasília, 18 de novembro 2011.

. Lei Complementar no 101, de 04 de maio de 2000: estabelece normas de finanças públicas voltadas para a responsabilidade na gestão fiscal e dá outras providências. Diário Oficial da União, Brasília, 05 maio 2000.

. Lei Complementar no 131, de 27 de maio de 2009: Acrescenta dispositivos à Lei Complementar no 101, de 4 de maio de 2000, que estabelece normas de finanças públicas voltadas para a responsabilidade na gestão fiscal e dá outras providências. Diário Oficial da União, Brasília, 28 maio 2009.

. Presidência da República. Projeto de Lei no 5.228 de 2009: Regula o acesso a informações previsto no Inciso XXXIII do Art. $5^{\circ}$, Inciso II do $₫ 3^{\circ} \mathrm{do}$ Art. 37 e no $\int 2^{\circ}$ do Art. 216 da Constituição. Brasília, 2009.

. Senado Federal. Projeto de Lei n ${ }^{\circ} 41$, de 30 abr. de 2010: Regula o acesso a informações previsto no Inciso XXXIII do Art. $5^{\circ}$, no Inciso II do $\int 3^{\circ}$ do Art. 37 e no $\int 2^{\circ}$ do Art. 216 da Constituição Federal; altera a Lei no 8.112, de 11 de dezembro de 1990; revoga a Lei no 11.111, de 5 de maio de 2005, e dispositivos. Brasília, 30 abr. 2010.

Canotilho, J. J. G. Estado de Direito. Cadernos Democráticos da Fundação Mário Soares, Lisboa, 1999.

Centro Internacional de Estudios de Transparencia y Acceso a la Información CETA. La cultura de los servidores públicos alrededor de los temas de transparencia y acceso a la información., [s.l.], 2007.

CEPIK, M. A. Direito à Informação: situação legal e desafios. IP - Informática Pública, Belo Horizonte, v. 2, n 2, p. 43-56, 2011.

Esmanhoto, A.M. La Transparencia y el Acceso a la Información en Brasil. DerecomRevista Online Especializada en Derecho de la Comunicación, [s.l.], nº 3, set-dez. 2010.

Foerstel, H.N. Freedom of Information and the Right to Know: The Origins and Applications of the Freedom of Information Act. Westport: Greenwood Press, 1999.

Foucault, M. Lecture of $1^{\circ}$ february 1978. In: Senellart, M.; Ewald, F.; Fontana, A. (Orgs.) Territory, population: Lectures at The Collège de France - Michel Foucult (1977-78). New York: Palgrave Macmillan, 2007.

Galeana, P. Information, archives and democracy. In: Fox, J.A. et. al. (Orgs.) Mexico's Right-to-know reforms: civil society perspectives, [s.l.]: Center for Global, International and Regional Studies, 2007.

Giddens, A. The Nation-State and Violence: Volume 2 of a Contemporary Critique of Historical Materialism. Cambridge: Polity Press, 1985.

JÁuregui, M.C. El derecho a la información: Delimitación conceptual. Derecho Comparado de la Información, México, no 15, Enero-Junio 2010. Disponível em: http:// biblio.juridicas.unam.mx/ revista/DerechoInformacion/indice.htm?n=15. Acesso em: 14 fev. 2011.

LEVY, J. L. Das restrições ao pedido de informações a órgão público. Revista Eletrônica de Direito de Estado, Salvador, jan./fev./mar. 2009. 
Lopes, C. A. Acesso à informação pública para a melhoria da qualidade dos gastos públicos - literatura, evidências empíricas e o caso brasileiro. Cadernos de Finanças Públicas, [s.l.], v. 1, no 8, p. 5-40, 2007.

Martins, P. O Direito a Informação no Brasil: uma visão da sociedade civil. Seminário Internacional sobre transparência e acesso à informação: desafios de implementação. Brasília, 07 e 08 ago. 2011.

Mendanha, G. M. M. O direito de acesso à informação como fundamento da transparência. Revista da CGU, Brasília, n. 6, set. 2009.

Mendel, T. Liberdade de informação: um estudo de direito comparado. $2^{\text {a }}$ ed. Brasília: UNESCO, 2009.

México. Ley federal de Transparencia y Aacceso a la Información Pública Gubernamental (2002). Diario Oficial de la Federación, México, 11 de junio de 2002.

NisBet, M. M. FOLA: accountability through transparency: democracy. Seminário Internacional sobre transparência e acesso à informação: desafios de implementação, Brasília, 07 e 08 jul. 2011.

PAES, E. B. O direito de saber. o acesso à informação governamental no Brasil a partir da Constituição de 1988 até a publicação da Lei no 12.527, de 2011. Dissertação de mestrado, Programa de Mestrado em Direito e Políticas Públicas do Centro Universitário de Brasília Uniceub, Brasília, 2011.

Pierini, A.; V. Lorences. Derecho de Acceso a la Información: por una democracia con efectivo control ciudadano - Acción de Amparo. Buenos Aires: Editorial Universidad, 1999.

Relly, J. Mexico Prepares for Open Government Laws. The Quill, s.l., v. 91, n 4, may 2003.

Roberts, A. Blacked Out: Government Secrecy in the Information Age. New York: Cambridge University Press, 2006.

SABA, R. El derecho de la persona a acceder a la información en poder del gobierno. Derecho Comparado de la Información, México, n 3, 2004.

Sweden. The Freedom of Press Act (1766). Disponível em http:/ /www.riksdagen.se/Global/ dokument/dokument/laws/the-freedom-of-the-press-act-2012.pdf. Acesso em: 20 fev. 2011.

United States Department of Justice. Celebrating FOIA's Forty-Fifth Anniversary \& Assessing This Past Year's Progress in Implementing Attorney General Holder's FOLA Guidelines. Disponível em: <www.foia.gov/2011 foiapost26.html>. Acesso em: 08 de set. 2011.

United States of America. The Freedom of Information Act(Foia) 5 U.S.C. \552, As Amended By Public Law No 104-231, 110 Stat. 3048 (1966). Disponivel em: http:// www.justice.gov/oip/foia_updates/Vol_XVII_4/page2.htm. Acesso em: 08 de set. 2011

Weber, M. Economía y Sociedad. Madrid: Fondo de Cultura Económica, 1994. 


\section{Resumo - Resumen - Abstract}

A construção da Lei de Acesso à Informação Pública no Brasil: desafios na implementação de seus princípios

Eneida Bastos Paes

Nos últimos anos, diversos países têm feito grandes modificações em suas legislações, na tentativa de proteger o direito de acesso à informação e adequar sua legislação interna às exigências impostas por tratados internacionais. A Lei de Acesso à Informação brasileira (Lei n ${ }^{\circ}$ 12.527, de 2011) foi construída a partir dos parâmetros internacionalmente reconhecidos. Esses parâmetros incorporam novos conceitos que ampliam o entendimento comum sobre o princípio da publicidade e recomendam a adoção do princípio da máxima transparência. A nova lei é essencial para melhorar as condições de acesso às informações governamentais no Brasil, como será mostrado na análise feita da experiência dos Estados Unidos da América e do México. Contudo, devido a dificuldades relacionadas especialmente à burocracia administrativa, o direito de acesso à informação tenderá a permanecer incompleto, enquanto não for incorporado a uma política pública capaz de traduzir esse direito em um conjunto de ações governamentais que garantam sua efetividade.

Palavras-Chave: acesso à informação, políticas públicas, lei de acesso, transparência.

La construcción de la Ley de Acceso a la Información Pública en Brasil: los desafíos en la aplicación de sus principios

Eneida Bastos Paes

En los últimos años, varios países han realizado cambios significativos en sus leyes en un intento de proteger el derecho de acceso a la información y adecuar su legislación interna con los requisitos impuestos por los tratados internacionales. La Ley de Acceso a la Información (Ley n 12527 de Brasil, de 2011) se construyó a partir de los parámetros reconocidos internacionalmente. Estos parámetros incorporaran nuevos conceptos que mejoran el entendimiento común sobre el principio de la publicidad y recomiendan la adopción del principio de la máxima transparencia. La nueva ley es esencial para mejorar las condiciones de acceso a la información pública en Brasil, como se muestra en el análisis de la experiencia de los Estados Unidos y México. Sin embargo, especialmente debido a las dificultades relacionadas con la burocracia administrativa, el derecho de acceso a la información tiende a permanecer incompleto hasta que se incorpore en una política pública que pueda traducir este derecho en un conjunto de acciones gubernamentales para garantizar su eficacia.

Palabras clave: acceso a la información, políticas públicas, ley de acceso, transparencia.

\section{Building the Access to Information Law in Brazil: challenges in implementing law principles \\ Eneida Bastos Paes}

In recent years, several countries have made significant changes to its laws in an attempt to protect the right of access to information and adapt their domestic law the requirements imposed by international treaties. The Law on Access to Information (Brazilian Law no 12527 of 2011) was constructed from the internationally recognized parameters. These parameters incorporate new concepts that enhance the common understanding on the principle of publicity and recommend the adoption of the principle of maximum transparency. As will be shown in the analysis of the experience of the United States and Mexico the new law is essential to improve 
the conditions of access to government information in Brazil. However, especially due to difficulties related to the administrative bureaucracy, the right of access to information will tend to remain incomplete until it is incorporated into a public policy that can translate this right into a set of government actions to ensure its effectiveness.

Keywords: access to information, public policy, law, access, transparency.

Eneida Bastos Paes

Mestre em Direito e Políticas Públicas pelo Centro Universitário de Brasília (UniCeub), especialista em Vigilância Sanitária e Monitoramento de Mercado pela Universidade de Brasília (UnB) e graduada em Ciências Jurídicas pela Universidade Federal de Ouro Preto (UFOP). Atualmente é Coordenadora do Núcleo de Elaboração Normativa e Acordos da Assessoria Jurídica da Controladoria-Geral da União (CGU).Contato: eneida.paes@gmail.com 